\title{
Interaction between inherited thrombophilia and HIV infection: fact or fancy?
}

Ida Martinelli, Valerio De Stefano and Pier Mannuccio Mannucci

We thank Michele Bibas, Gianluigi Biava, and Andrea Antinori for their Correspondence (HIV infection as a permanent, acquired risk factor for VTE. Nat. Rev. Cardiol. doi:10.1038/nrcardio.2013.211-c1 $)^{1}$ on our Review article (Martinelli, I. et al. Inherited risk factors for venous thromboembolism. Nat. Rev. Cardiol. 11, 140-156 [2014]), ${ }^{2}$ and their comments regarding HIV infection as a risk factor for venous thromboembolism (VTE). This association has been definitely established in a Danish population-based study. ${ }^{3}$ In Box 1 of our Review, ${ }^{2}$ we identified that infectious diseases are associated with an increased risk of VTE, ${ }^{4}$ but avoided detailing particular infectious agents. For example, acute Cytomegalovirus infection, which is far more common than HIV infection, doubles the risk of VTE. ${ }^{5}$ Other well-established risk factors for VTE are Staphylococcus aureus infection ${ }^{6}$ and active tuberculosis. ${ }^{7}$ More broadly, in a large population-based study, respiratory tract, urinary tract, skin, gastrointestinal, and bacteraemic infections diagnosed in the community or in hospital were associated with a 2.6 -fold to 3.3-fold increased risk of VTE after adjustment for other factors. ${ }^{8}$ As Bibas et al. correctly point out, ongoing opportunistic infections can further increase the risk of VTE in patients infected with HIV. ${ }^{9}$ We agree that infections and inherited thrombophilia might have a synergic effect on the risk of VTE, as demonstrated for pneumonia and factor $\mathrm{V}$ Leiden or prothrombin G20210A. ${ }^{10}$ However, no data are available on the interaction between HIV infection and thrombophilia on the risk of VTE. Therefore, the statement that patients who are infected with HIV and carry one of the common mild thrombophilia abnormalities should be considered at higher risk of VTE than individuals who are not infected with HIV remains speculative. Considering that combined antiretroviral therapy might increase the risk of VTE, ${ }^{3}$ we prefer not to cause unwarranted alarm in the 6-8\% of patients with HIV who carry heterozygous factor $V$ Leiden or the prothrombin mutation with assumptions that are not evidence-based.

Angelo Bianchi Bonomi Hemophilia and Thrombosis Center, Fondazione IRCCS Ca' Granda, Ospedale Maggiore Policlinico, Via Pace 9, 20122 Milan, Italy (I.M.). Institute of Hematology, Catholic University, Largo A. Gemelli 8, I-00168 Rome, Italy (V.D.S.). Scientific Direction, Fondazione IRCCS Ca' Granda, Ospedale Maggiore Policlinico, Via F. Sforza 28, 20122 Milan, Italy (P.M.M.).

Correspondence to: P.M.M.

pm.mannucci@policlinico.mi.it

\section{Competing interests}

The authors declare no competing interests.

1. Bibas, M., Biava, G. \& Antinori, A. HIV infection as a permanent, acquired risk factor for VTE. Nat. Rev. Cardiol. http://dx.doi.org/10.1038/ nrcardio.2013.211-c1.
2. Martinelli, I., De Stefano, V. \& Mannucci, P. M. Inherited risk factors for venous thromboembolism. Nat. Rev. Cardiol. 11, 140-156 (2014).

3. Rasmussen, L. D. et al. HIV and risk of venous thromboembolism: a Danish nationwide population-based cohort study. HIV Med. 12, 202-210 (2011).

4. Samama, M. M. An epidemiologic study of risk factors for deep vein thrombosis in medical outpatients: the Sirius study. Arch. Intern. Med. 160, 3415-3420 (2000).

5. Paran, Y. et al. Thrombosis following acute cytomegalovirus infection: a community prospective study. Ann. Hematol. 92, 969-974 (2013).

6. Mejer, N. et al. Increased risk of venous thromboembolism within the first year after Staphylococcus aureus bacteraemia: a nationwide observational matched cohort study. J. Intern. Med. http://dx.doi.org/ 10.1111/joim.12147.

7. Dentan, C., Epaulard, O., Seynaeve, D., Genty, C. \& Bosson, J. L. Active tuberculosis and venous thromboembolism: association according to International Classification of Diseases, Ninth Revision hospital discharge diagnosis codes. Clin. Infect. Dis. 58, 495-501 (2014).

8. Schmidt, M., Horvath-Puho, E., Thomsen, R. W., Smeeth, L. \& Sørensen, H. T. Acute infections and venous thromboembolism. J. Intern. Med. 271, 608-618 (2012).

9. Crum-Cianflone, N. F., Weekes, J. \& Bavaro, M. Review: thromboses among HIV-infected patients during the highly active antiretroviral therapy era. AIDS Patient Care STDS 22, 771-778 (2008).

10. Ribeiro, D. D., Lijfering, W. M., Van Hylckama Vlieg, A., Rosendaal, F. R. \& Cannegieter, S. C. Pneumonia and risk of venous thrombosis: results from the MEGA study. J. Thromb. Haemost. 10, 1179-1182 (2012). 